\title{
EFFECT OF DEXMEDETOMIDINE ON HAEMODYNAMIC AND RECOVERY RESPONSES DURING TRACHEAL EXTUBATION: A RANDOMIZED COMPARATIVE STUDY
}

\author{
Sarada Devi Vankayalapati1, Manjula V. Ramsali², Suguna Dumpala3 ${ }^{3}$ Surender Pasupuleti ${ }^{4}$ \\ ${ }^{1}$ Assistant Professor, Department of Anaesthesia, Mallareddy Medical College for Women, Hyderabad. \\ ${ }^{2}$ Assistant Professor, Department of Anaesthesia, Mallareddy Medical College for Women, Hyderabad. \\ ${ }^{3}$ Assistant Professor, Department of Community Medicine, Mallareddy Medical College for Women, Hyderabad. \\ 4 Professor and HOD, Department of Anaesthesia, Mallareddy Medical College for Women, Hyderabad.
}

\begin{abstract}
This study was undertaken to evaluate the effect of a bolus dose of dexmedetomidine on haemodynamic, recovery responses and airway reflexes during extubation.

\section{MATERIAL AND METHODS}

Sixty patients aged 20-45 yrs. of either sex of ASA grade I/II scheduled for elective general surgical, ENT, orthopaedics and gynaecological surgeries were studied after randomisation into two groups; 5 minutes before anticipated end of surgery, group A and B received either dexmedetomidine $0.5 \mu \mathrm{g} / \mathrm{kg}$ or placebo (Saline) respectively intravenously over 2 minutes. Anaesthesia technique was standardised for both groups. Heart rate, systolic, diastolic, mean arterial pressures were recorded at the start of a bolus drug injection and thereafter 1, 2 and 3 minutes after injection during extubation; at 1, 3, 5 minutes after extubation for 15 minutes. Quality of extubation was evaluated immediately after extubation based on cough using a 5-point rating score. Postoperative sedation was evaluated on a 6-point scale (Ramsay sedation scale). Side effects like laryngospasm, bronchospasm, respiratory depression, desaturation, vomiting, hypotension, bradycardia and undue sedation were noted.
\end{abstract}

\section{RESULTS}

Heart rate, systolic, diastolic, mean arterial pressure were significantly lower in study group. Extubation quality score in majority of cases was score 1 in study group and score 3 in control group. Sedation score in most of the cases was 3 in study group and 2 in control group. Bradycardia and hypotension were more in study group. Vomiting incidence was comparable in both the groups.

\section{CONCLUSION}

Our study concludes that single dose of dexmedetomidine $0.5 \mu \mathrm{g} / \mathrm{kg}$ administered 5 minutes before extubation attenuates the haemodynamic and airway reflexes during emergence from anaesthesia without causing undue sedation.

\section{KEYWORDS}

Dexmedetomidine, Haemodynamic Responses, Airway Reflexes, Extubation.

HOW TO CITE THIS ARTICLE: Vankayalapati SD, Ramsali MV, Dumpala S, et al. Effect of dexmedetomidine on haemodynamic and recovery responses during tracheal extubation: a randomized comparative study. J. Evolution Med. Dent. Sci. 016;5(46):2880-2883, DOI: $10.14260 /$ jemds/2016/671

\section{INTRODUCTION \\ Emergence from anaesthesia and tracheal extubation are usually associated with hypertension, tachycardia and high plasma catecholamines leading to increased systemic vascular resistance and myocardial contractility. ${ }^{1}$ The peak changes are noticed about one minute following extubation and continue until 10 minutes. Majority of the patients tolerate these changes without any significant clinical consequences, but patients suffering from diseases like hypertension, diabetes, CAD, etc. may not tolerate these responses. ${ }^{2}$ \\ Various agents like lidocaine, opioids, esmolol, fentanyl, calcium channel blockers, magnesium sulphate and propofol have been shown to attenuate these responses, but they have limitations and side effects. 3,4}

Financial or Other, Competing Interest: None

Submission 11-04-2016, Peer Review 19-05-2016,

Acceptance 24-05-2016, Published 08-06-2016.

Corresponding Author:

Dr. Sarada Devi Vankayalapati,

Villa-16, Beverly Palms, Nizampet,

Opposite Kesineni Bus Depot,

Hyderabad-500090.

E-mail: drsarada_devi@yahoo.com

DOI: $10.14260 /$ jemds $/ 2016 / 671$
Alpha-2-Adrenergic Receptor (AR) agonists have been the focus of interest for their sedative, analgesic, perioperative sympatholytic, anaesthetic sparing and haemodynamic stabilizing properties. Dexmedetomidine a highly selective $\alpha_{2}$ AR agonist possesses all these properties, but lacks respiratory depression making it a useful and safe adjunct in diverse clinical applications. ${ }^{5}$ It has 8 times more affinity compared with clonidine and suppresses the release of catecholamines to stress response.

This drug may be useful in anaesthetic management requiring smooth emergence from anaesthesia. The net effect of dexmedetomidine action is a significant reduction in circulating catecholamines with a slight decrease in blood pressure and a modest reduction in heart rate. Because of its anxiolytic and analgesic qualities and lack of respiratory depression, dexmedetomidine could be an attractive alternative. ${ }^{6}$ Dexmedetomidine can provide a dose dependant cooperative sedation that allows ready interaction with the patient. 7

Our study was designed to determine the effects of a single bolus dose of dexmedetomidine as an effective drug to attenuate the haemodynamic and recovery responses during emergence from general anaesthesia and tracheal extubation. 


\section{MATERIAL AND METHODS}

This clinical study was carried out at Mallareddy Medical College for Women, Hyderabad, during June 2015 to Feb 2016 on sixty patients ( 30 in each group) between 20 to 45 years of age of either sex belonging to ASA physical status I and II and scheduled for elective general surgical, ENT, orthopaedic and gynaecological surgery under general anaesthesia. Patients suffering from cardiovascular, respiratory disorders, diabetes, hypertension, obesity, difficult airway, history of sleep apnoea, pregnancy, breast feeding women and medications that affect heart rate or blood pressure and emergency procedures were excluded from the study.

Institutional board approval was obtained. Preanaesthetic check-up was conducted and a detailed history and a complete physical examination recorded. Routine investigations like complete blood picture, blood grouping and typing, blood urea, serum creatinine, bleeding time, clotting time, blood sugar, ECG and chest radiography were done. Written informed consent was taken from each patient.

Patients were randomly divided into 2 groups of 30 each. Randomization was done by computer generated table.

- Group A: Study group (Dexmedetomidine)

- Group B: Control group (Normal saline)

Anaesthesia technique was standardized for both groups using propofol, fentanyl, vecuronium, nitrous oxide-oxygen and isoflurane. Standard monitoring consisted of ECG, pulse oximetry $\left(\mathrm{Spo}_{2}\right), \mathrm{EtCO}_{2}$ and non-invasive blood pressure. Inhalational agent was cut-off 5 minutes before the estimated time of end of surgery and patients in each group received the specified solution intravenously over 2 minutes.

Patients in group A received dexmedetomidine $0.5 \mu \mathrm{g} / \mathrm{kg}$ IV in $10 \mathrm{~mL}$ saline over 2 minutes, while in group B patients received $10 \mathrm{~mL}$ saline over 2 minutes.

Heart rate, systolic, diastolic and mean arterial blood pressures were recorded at the start of a bolus drug injection and thereafter 1, 2, 3 minutes. Residual neuromuscular blockade was reversed with neostigmine and glycopyrrolate. When spontaneous respirations were sufficient and able to obey simple commands, suction of the throat was done and trachea was extubated.

The anaesthesiologist performing the extubation was blinded to the study drugs. Heart rate, systolic, diastolic and mean arterial blood pressure were recorded at the time of extubation and thereafter 1, 3, 5, 10 and at 15 minutes after extubation. Any side effects like laryngospasm, bronchospasm, respiratory depression, desaturation, vomiting, hypotension, bradycardia and undue sedation were noted.

Hypotension was defined as a decrease in systolic blood pressure of more than $20 \%$ decrease from baseline or systolic blood pressure less than $80 \mathrm{mmHg}$. Bradycardia was defined as heart rate of less than $60 / \mathrm{min}$.

Quality of extubation was evaluated based on cough immediately after extubation, using a 5-point rating scale. ${ }^{8}$

1. No coughing.

2. Smooth extubation with minimal coughing ( 1 or 2 times).

3. Moderate coughing ( 3 or 4 times).

4. Severe coughing (5 to 10 times) and straining.

5. Poor extubation, very uncomfortable (Laryngospasm and coughing $>10$ times).

Post-operative sedation was evaluated 5 minutes after extubation on a 6-point scale (Ramsay sedation scale). ${ }^{9}$
1. Anxious or agitated and restless or both.

2. Cooperative, oriented and tranquil.

3. Drowsy, but responds to commands.

4. Asleep, brisk response to glabellar tap or loud auditory stimulus.

5. Asleep and slow response to stimulation, 6-asleep and unarousable, no response to stimulation.

According to statistical power analysis, 24 patients per treatment group were needed to get an $80 \%$ power in detecting a $30 \%$ difference between treatment groups with a $5 \%$ type 1 error. We conducted a study with 30 patients in each group. The parameters were recorded and data was entered into Statistical Package for Social Sciences (SPSS 20.0). Statistical analysis was done using paired samples t-test for between group comparisons. P value $<0.05$ was considered as statistically significant.

\section{RESULTS}

Patients in the two groups were comparable for age, weight, male:female ratio, ASA physical status, Mallampati class, nature of surgery and were not significantly different between the two groups [Table 1].

We observed a statistically significant difference $(\mathrm{p}<0.05)$ in heart rate between the two groups from 2 minutes after starting administration of the agent till 15 minutes after extubation (Table 3). No significant increase in heart rate after extubation in dexmedetomidine group compared with preextubation value. There was a significant increase in heart rate in control group (Table 2).

A statistically significant difference $(\mathrm{p}<0.05)$ was observed in systolic blood pressure between the two groups from $2 \mathrm{~min}$ after the start of the administration of the agent and continued till the time observations were made (Table 3). Our study showed a significant difference in diastolic and mean arterial blood pressure between the two groups $(\mathrm{p}<0.05)$ from $3 \mathrm{~min}$ after starting the administration of the agent and continued till the time observations were made $(p<0.05)$.

There was a statistically significant difference $(p<0.05)$ in the quality of extubation between the two groups $(\mathrm{p}<0.05)$ (Table 4); $60 \%$ of the patients in group A could be extubated smoothly without any cough, whereas $40 \%$ of the patients showed minimal coughing at the time of extubation, whereas only $33 \%$ of the patients could be extubated smoothly with minimal coughing. Majority of the patients in group B showed moderate coughing at the time of extubation (Table 4). A significant difference in the level of post-operative sedation was observed between the two groups $(\mathrm{p}<0.05)$ (Table 5); $90 \%$ of the patients in group A were drowsy, but responding to verbal commands with the sedation score of 3 on the Ramsay scale, whereas in group B 93\% of the patients were cooperative, oriented and tranquil with a sedation score of 2 on the Ramsay scale (Table 5).

One patient in group A had bradycardia, but none in group B; two patients in group A developed hypotension, whereas none in group B; but none of the patients in either group required treatment for bradycardia or hypotension.

Incidence of vomiting was more in group B. Other side effects like respiratory depression, laryngospasm, bronchospasm or undue sedation were not observed in either of the groups (Table 6). No significant difference was observed between the two groups in $\mathrm{SpO}_{2}$ values. 


\begin{tabular}{|c|c|c|}
\hline Description & $\begin{array}{c}\text { Study Group } \\
\text { (Group A) } \\
\text { Mean } \pm \text { SD }\end{array}$ & $\begin{array}{c}\text { Control Group } \\
\text { (Group B) } \\
\text { Mean } \pm \text { SD }\end{array}$ \\
\hline Age (In years) & $34.93 \pm 7.21$ & $33 \pm 6.93$ \\
\hline Male:Female & $11: 19$ & $10: 20$ \\
\hline Weight & $63.43 \pm 7.95$ & $62.43 \pm 6.84$ \\
\hline ASA & I/II & I/II \\
\hline MP Grade & I/II & I/II \\
\hline \multicolumn{2}{|c|}{ Table 1: Demographic Profile } \\
\hline
\end{tabular}
groups.
Demographic data were not statistically different among

\begin{tabular}{|c|c|c|c|}
\hline \multirow{2}{*}{ Description } & \multicolumn{3}{|c|}{ Heart Rate } \\
\cline { 2 - 4 } & Group A & Group B & P Value \\
\hline Baseline & $84.13 \pm 9.126$ & $84 \pm 8.990$ & 0.955 \\
\hline 1 min & $83.40 \pm 8.712$ & $84.60 \pm 8.017$ & 0.582 \\
\hline $2 \mathrm{~min}$ & $80.67 \pm 8.491$ & $86.07 \pm 8.229$ & 0.015 \\
\hline $3 \mathrm{~min}$ & $78.47 \pm 8.349$ & $86.47 \pm 7.977$ & 0.000 \\
\hline $\begin{array}{c}\text { Before } \\
\text { Extubation }\end{array}$ & $79.20 \pm 7.676$ & $86.60 \pm 7.596$ & 0.000 \\
\hline 1 min & $81.80 \pm 7.490$ & $92.67 \pm 8.458$ & 0.000 \\
\hline 3 min & $80.47 \pm 8.182$ & $94.20 \pm 7.416$ & 0.000 \\
\hline 5 min & $78.27 \pm 7.404$ & $92.87 \pm 6.511$ & 0.000 \\
\hline $10 \mathrm{~min}$ & $76.00 \pm 7.575$ & $91.47 \pm 6.642$ & 0.000 \\
\hline $15 \mathrm{~min}$ & $74.27 \pm 7.732$ & $89.67 \pm 6.687$ & 0.000 \\
\hline \multicolumn{4}{|c|}{ Table 2: Heart Rate Changes } \\
\hline \multicolumn{4}{|c}{} \\
\hline
\end{tabular}

\begin{tabular}{|c|c|c|c|c|c|c|c|c|c|}
\hline \multirow[b]{2}{*}{ Description } & \multicolumn{3}{|c|}{ Systolic Blood Pressure } & \multicolumn{3}{|c|}{ Diastolic Blood Pressure } & \multicolumn{3}{|c|}{ Mean Arterial Pressure } \\
\hline & $\begin{array}{c}\text { Group } \\
\text { A }\end{array}$ & $\begin{array}{c}\text { Group } \\
\text { B } \\
\end{array}$ & $\begin{array}{c}\mathbf{P} \\
\text { Value }\end{array}$ & $\begin{array}{c}\text { Group } \\
\text { A }\end{array}$ & $\begin{array}{c}\text { Group } \\
\text { B } \\
\end{array}$ & $\begin{array}{c}\mathbf{P} \\
\text { Value }\end{array}$ & $\begin{array}{c}\text { Group } \\
\text { A }\end{array}$ & $\begin{array}{c}\text { Group } \\
\text { B }\end{array}$ & $\begin{array}{c}P \\
\text { Value }\end{array}$ \\
\hline Baseline & $121.47 \pm 7.181$ & $121.40 \pm 6.891$ & 0.971 & $78.67 \pm 4.992$ & $74.20 \pm 4.437$ & 0.001 & $92.90 \pm 4.901$ & $89.97 \pm 3.728$ & 0.012 \\
\hline $1 \mathrm{~min}$ & $120 \pm 6.486$ & $120.80 \pm 5.933$ & 0.649 & $76.53 \pm 4.925$ & $70.00 \pm 19.518$ & 0.081 & $90.93 \pm 4.727$ & $90.30 \pm 3.436$ & 0.555 \\
\hline $2 \min$ & $116.53 \pm 5.941$ & $120.67 \pm 6.133$ & 0.01 & $74.67 \pm 4.436$ & $75.53 \pm 4.091$ & 0.435 & $88.70 \pm 4.466$ & $90.53 \pm 3.481$ & 0.081 \\
\hline $3 \mathrm{~min}$ & $113.83 \pm 5.849$ & $121.33 \pm 5.616$ & 0.000 & $72 \pm 4.668$ & $76.60 \pm 3.450$ & 0.000 & $86.10 \pm 4.389$ & $91.43 \pm 2.956$ & 0.000 \\
\hline $\begin{array}{c}\text { Before } \\
\text { Extubation }\end{array}$ & $114.20 \pm 5.927$ & $121.13 \pm 5.625$ & 0.000 & $73.77 \pm 4.739$ & $75.73 \pm 3.704$ & 0.079 & $86.90 \pm 4.113$ & $90.93 \pm 3.226$ & 0.000 \\
\hline $1 \mathrm{~min}$ & $117.53 \pm 5.191$ & $126.13 \pm 5.823$ & 0.000 & $75.47 \pm 4.392$ & $79.27 \pm 3.769$ & 0.001 & $89.47 \pm 3.758$ & $94.77 \pm 3.319$ & 0.000 \\
\hline $3 \mathrm{~min}$ & $114.27 \pm 5.502$ & $125.40 \pm 5.334$ & 0.000 & $73.67 \pm 4.2055$ & $79.13 \pm 3.589$ & 0.000 & $87.23 \pm 3.884$ & $94.57 \pm 2.881$ & 0.000 \\
\hline $5 \mathrm{~min}$ & $111.80 \pm 4.374$ & $123.12 \pm 5.575$ & 0.000 & $72.00 \pm 4.102$ & $77.80 \pm 3.690$ & 0.000 & $85.07 \pm 3.393$ & $93.00 \pm 3.434$ & 0.000 \\
\hline $10 \mathrm{~min}$ & $109.67 \pm 4.003$ & $121.20 \pm 4.999$ & 0.000 & $70.67 \pm 3.977$ & $76.33 \pm 3.407$ & 0.000 & $83.80 \pm 2.858$ & $91.37 \pm 3.135$ & 0.000 \\
\hline $15 \mathrm{~min}$ & $108.73 \pm 4.051$ & $119.73 \pm 5.626$ & 0.000 & $68.73 \pm 4.623$ & $75.53 \pm 3.431$ & 0.000 & $82.03 \pm 3.855$ & $90.23 \pm 3.036$ & 0.000 \\
\hline
\end{tabular}

\begin{tabular}{|c|c|c|}
\hline Score & Group A & Group B \\
\hline 1 & 18 & 0 \\
\hline 2 & 12 & 10 \\
\hline 3 & 0 & 20 \\
\hline 4 & 0 & 0 \\
\hline 5 & 0 & 0 \\
\hline \multicolumn{2}{|c|}{ Table 4: Extubation Quality Score } \\
\hline
\end{tabular}

\begin{tabular}{|c|c|c|}
\hline Scale & Group A & Group B \\
\hline 1 & 0 & 2 \\
\hline 2 & 7 & 28 \\
\hline 3 & 23 & 0 \\
\hline 4 & 0 & 0 \\
\hline 5 & 0 & 0 \\
\hline 6 & 0 & 0 \\
\hline \multicolumn{2}{|c|}{ Table 5: Ramsay Sedation Scale } \\
\hline
\end{tabular}

\begin{tabular}{|c|c|c|c|c|c|}
\hline \multirow{2}{*}{$\begin{array}{c}\text { Sl. } \\
\text { No. }\end{array}$} & \multirow{2}{*}{$\begin{array}{c}\text { Side } \\
\text { Effects }\end{array}$} & \multicolumn{2}{c|}{$\begin{array}{c}\text { Group A } \\
\mathbf{n}=\mathbf{3 0}\end{array}$} & $\begin{array}{c}\text { Group B } \\
\mathbf{n = 3 0}\end{array}$ \\
\cline { 3 - 6 } & & $\mathbf{N o .}$ & $\mathbf{\%}$ & No. & $\mathbf{\%}$ \\
\hline 1 & Bradycardia & 1 & 3 & 0.0 & 0.0 \\
\hline 2 & Tachycardia & 0.0 & 0.0 & 2 & 7 \\
\hline 3 & Hypotension & 2 & 7 & 0.0 & 0.0 \\
\hline 4 & Vomiting & 1 & 3 & 2 & 7 \\
\hline 5 & Laryngospasm & 0.0 & 0.0 & 0.0 & 0.0 \\
\hline 6 & Bronchospasm & 0.0 & 0.0 & 0.0 & 0.0 \\
\hline 7 & Undue Sedation & 0.0 & 0.0 & 0.0 & 0.0 \\
\hline \multicolumn{7}{|c|}{ Table 6: Comparison of Side Effects } \\
\hline
\end{tabular}

\section{DISCUSSION}

Emergence from general anaesthesia and tracheal extubation are often accompanied by tachycardia and hypertension and is of equal concern as intubation response.10 These responses may produce myocardial ischemia or infarction in susceptible patients. Alpha-2-Adrenergic Receptor (AR) agonists decrease the sympathetic outflows and noradrenergic activity, thereby counteracting haemodynamic fluctuations occurring at the time of intubation. ${ }^{5}$

Dexmedetomidine is a new alpha 2 agonist, suppresses the release of catecholamines to stress response. The present study was conducted to evaluate the effect of dexmedetomidine in a dose of $0.5 \mu \mathrm{g} / \mathrm{kg}$ (as a single bolus dose) on haemodynamic response during extubation, the quality of extubation, the level of post-operative sedation and the prevalence of complications. We found that the cough reflex, increase in systolic and diastolic arterial pressure, heart rate associated with emergence from anaesthesia were attenuated by a single bolus dose of dexmedetomidine 0.5 $\mu \mathrm{g} / \mathrm{kg}$.

In group A, we observed that HR showed insignificant rise compared to basal value from second minute of drug administration, at extubation and post-extubation period. But in group B, there was a significant rise in HR compared to basal done by Shirang Rao et al. ${ }^{2}$

Systolic (SBP), Diastolic (DBP) and Mean Arterial Pressures (MAP) values are significantly lower in group A compared to baseline values at all times from the time of injection of dexmedetomidine to post-extubation for 15 minutes. This is in conjunction with the study conducted by Bindu et al. ${ }^{11}$

Bradycardia was observed in one patient (3.3\%) and hypotension in two patients (7\%) in group A, but none in group B. This was not statistically significant. None of the patients required treatment for bradycardia and hypotension. This is in conjunction with observations by Guler et al. ${ }^{12}$

Turan et al found that dexmedetomidine $0.5 \mu \mathrm{g} / \mathrm{kg}$ administered 5 minutes before the end of surgery stabilized haemodynamics, allowed easy extubation, provided a more values. These observations were in concurrence with the study 
comfortable recovery and early neurological examination following intracranial operations. ${ }^{8}$

Turan et al, studied the effects of two different doses of dexmedetomidine during the extubation period in patients operated for intracranial lesions. They concluded that dexmedetomidine used in a dose of $0.5 \mu \mathrm{g} / \mathrm{kg}, 1$ minute before extubation is a suitable agent for optimal haemodynamic state and good recovery condition for intracranial operations. ${ }^{8}$

In our study, we observed a significant difference in the quality of extubation between the group A and group B; $60 \%$ of the patients in group A could be extubated smoothly without any cough, whereas $33 \%$ of the patients could be extubated smoothly with minimal coughing. This is in conjunction with the observation by Aksu R et al. ${ }^{13}$

$\mathrm{SPO}_{2}$ values were comparable in both the groups with no significant difference was observed in $\mathrm{SPO}_{2}$ values, no incidence of desaturation. No side effects like bronchospasm, laryngospasm, respiratory depression or undue sedation were noticed in either of the groups. These observations are in concurrence with study conducted by Guler et al. ${ }^{12}$

Sedation in our study was assessed by using Ramsay Sedation Scale. Significant numbers of patients in group A were drowsy, but responded to verbal commands (Ramsay Sedation Scale 3) when compared to group B, where most patients with sedation score was 2 on the Ramsay Scale. This is in conjunction with the study conducted by Bindu et al.11 The need for post-operative analgesia was delayed in group A compared to group B. This is in conjunction with the study done by Sharma VB. ${ }^{14}$

Our study found insignificant difference in the incidence of vomiting between two groups.

\section{CONCLUSION}

We conclude our study that a single bolus dose of dexmedetomidine $0.5 \mu \mathrm{g} / \mathrm{kg}$ administered 5 minutes before tracheal extubation attenuates the airway and haemodynamic reflexes during emergence from anaesthesia. It enables smooth extubation of the trachea and provides adequate sedation with minimal side effects post-operatively.

\section{REFERENCES}

1. Moustafa AM, Atalla H, Koptan HM. Comparison of dexmedetomidine, lidocaine and their combination in attenuation of cardiovascular and catecholamine responses to tracheal extubation and anaesthesia emergency in hypertensive patients. Res Opin Anaesth Intensive Care 2015;1(1):1-6.

2. Shrirang R, Somasekharam P, Dinesh K, et al. Effect of bolus dose of dexmedetomidine on haemodynamic responses and airway reflexes during tracheal extubation: double blind randomized, controlled trial study. World Journal of pharmacy and pharmaceutical sciences 2015;4(3):731-40.
3. Minogue SC, Ralph J, Lampa MJ. Laryngotracheal topicalization with lidocaine before intubation decreases the incidence of coughing on emergence from general anaesthesia. Anaesth Analg 2004;99(4):1253-7.

4. Aouad MT, Al-Alami AA, Nasr VG, et al. The effect of low dose remifentanil on responses to the endotracheal tube during emergence from general anaesthesia. Anaesth Analg 2009;108(4):1157-60.

5. Anju Grewal. Dexmedetomidine: new avenues. J Anaesthesiol Clin Pharmacol 2011;27(3):297-302.

6. Qing Fan, Chunbo Hu, Min Ye, et al. Dexmedetomidine for tracheal extubation in deeply anaesthetized adult patients after otological surgery: a comparison with remifentanil. BMC Anaesthesiology 2015;15:106.

7. Sulaiman S, Karthekeyan RB, Vakamudi M, et al. The effects of dexmedetomidine on attenuation of stress response to endotracheal intubation in patients undergoing elective off-pump coronary artery bypass grafting. Ann Card Anaesth 2012;15(1):39-43.

8. Turan G, Ozgultekin A, Turan C, et al. Advantageous effects of dexmedetomidine on haemodynamic and recovery responses during extubation for intracranial surgery. Eur J Anaesthesiol 2008;25(10):816-20.

9. Ramsay MA, Huddleston P, Hamman B, et al. The patient state index correlates well with the ramsay sedation score in ICU patients. Anaesthesiology 2004;101:338.

10. Kayhan Z, Aldemir D, Mutlu H, et al. Which is responsible for the haemodynamic response due to the laryngoscopy and endotracheal intubation? Catecholamines, vasopressin or angiotensin? Eur J Anaesthesiol 2005;22(10):780-5.

11. Bindu B, Pasupuleti S, Gowd UP, et al. A double blind, randomized, controlled trial to study the effect of dexmedetomidine on haemodynamic and recovery responses during tracheal extubation. J Anaesthesiol Clin Pharmacol 2013;29(2):162-7.

12. Guler G, Akin A, Tosun Z, et al. Single-dose dexmedetomidine attenuates airway and circulatory reflexes during extubation. Acta Anaesthesiol Scand 2005;49(8):1088-91.

13. Aksu R, Akin A, Bicer C, et al. Comparison of the effects of dexmedetomidine versus fentanyl on airway reflexes and haemodynamic responses to tracheal extubation during rhinoplasty: a double-blind, randomized, controlled study. Curr Ther Res Clin Exp 2009;70(3):209-20.

14. Sharma VB, Prabhakar H, Rath GP, et al. Comparison of dexmedetomidine and lignocaine on attenuation of airway and pressor responses during tracheal extubation. J Neuroanaesthesiol and Crit Care 2014;1(1):50-5. 